Ophthalmologica 1961;141:434

\title{
Partialokklusion mit Polarisationsgläsern
}

$\mathrm{H}$.

Gernet

\section{Genève}

Erschien ausführlich in Ophthalmologica 141: 220-228 (1961).

Schweiz. Ophthal. (ies. 53. Jahresvers., Basel 1960 Ophthalmologica 141: 434 (1961)

Sehneirverlängerung nach Gonin

Von F. HOLLWICH (Jena) Erscheinl später ausführlich in dieser Zeitschrift. 